\title{
Split It! Let's Break That Stress - A Case Report
}

\author{
Abhijit Patil ${ }^{1}$, Tanya Sethi², Mallikarjun H. Doddamani³ ${ }^{3}$ Rutvi Shah ${ }^{4}$, \\ Anandkumar G. Patil ${ }^{5}$, Ankeet Vora6 ${ }^{6}$, Twisha Dave ${ }^{7}$, Divya Joshi ${ }^{8}$
}

\begin{abstract}
1, 3, 4, 5, 8 Department of Prosthodontics and Crown and Bridge, KAHER's KLE Vishwanath Katti Institute of Dental Sciences, Belgaum, Karnataka, India, ${ }^{2}$ Department of Prosthodontics, Procure Dental, Bangalore, Karnataka, India. ${ }^{6}$ Sabka Dentist Dental Clinic, Ahmadabad, Gujarat, India. ${ }^{7}$ Clove Dental Clinic, Ahmadabad, Gujarat, India.
\end{abstract}

\section{INTRODUCTION}

Fixed prosthodontics is a zestful and progressing branch because of the numerous advantages that it has over removable prosthesis. The oral cavity for each scenario has its own complications and hence every individual case has its own approach keeping in mind the comfort, function, and aesthetics of the patient. In some cases, we come across an edentulous space on both the sides, creating a lone free-standing tooth. This clinical scenario with a pier abutment needs to be taken into consideration during restoration of the arch as the masticatory forces applied on the abutment teeth at one end of fixed partial denture (FPD) can result in the pier abutment acting as a fulcrum resulting in ultimate failure of the FPD and trauma to the periodontium. To overcome this complication, use of non-rigid connectors is advised. Many innovative clinical designs with modifications to the conventional bridges have been proposed over the years to undertake such a scenario most diligently. Selection of the right type of connector is imperative for the success while undertaking such a case. This era is of digital dentistry; hence, an innovative, time saving, and cost-effective way of fabricating non-rigid connector using Exocad software and 3D printing of split pontic FPD is presented in this case report.

Masticatory forces and occlusal loads applied to a fixed partial denture (FPD) are transmitted to the supporting structures through the pontic connectors, and retainers. ${ }^{1}$ An FPD with the pontic firmly stable on the retainer will provide stability to the prosthesis along with minimizing the stresses associated with the restoration. However, in case of a pier abutment with edentulous space occurring on both the sides; the physiologic tooth movement, position of the abutment tooth in the arch, and a disparity in the retentive capability of the retainers can make a long span FPD a less than ideal treatment plan. ${ }^{2}$

The choice of a pontic is considered crucial for abutments, since maximum stresses are concentrated on them under occlusal loading. The selection of the most favourable type of connector is essential for the success of the prosthesis. ${ }^{3,4}$ Various researchers have given different locations of connectors in FPD. There are many areas of dentistry where digital technology is used today. Each area of digital dentistry has advantage over the conventional techniques. Hence in this case report, Matrix and Patrix system of the connector were fabricated using Exocad software and 3-D printed framework was tried and final prosthesis was fabricated using CAM. It has numerous advantages over conventional techniques.

They are as follows -

1. Less time consuming

2. Less technique sensitive

3. Cost effective as compared to the precision and semi-precision attachments

4. Accurate fit of the prosthesis

Split pontic has several privileges over conventional connectors like conservative preparation of all abutments, anterior abutment neither requires distal box preparation to accommodate the female attachment, nor does the tilted abutment requires over reduction. The interface between the two pontic halves is constructed away from the tissue and occlusal surface of the pontic, hence obliterating the difficulties like hygiene and occlusion. Increased stability is another added advantage of placing the attachment in the pontic. ${ }^{5}$

\author{
Corresponding Author: \\ Dr. Abhijit Patil, \\ Lecturer, \\ Department of Prosthodontics and \\ Crown and Bridge, KAHER'S, \\ KLE Vishwanath Katti Institute of \\ Dental Sciences, Belgaum, \\ Karnataka, India. \\ E-mail:dr.abhijitpatil85@gmail.com
}

DOI: $10.14260 / j e m d s / 2021 / 372$

How to Cite This Article:

Patil A, Sethi T, Doddamani MH, et al. Split

it! let's break that stress - a case report. J Evolution Med Dent Sci 2021;10(23):18031806, DOI: $10.14260 /$ jemds/2021/372

Submission 03-02-2021,

Peer Review 14-04-2021,

Acceptance 20-04-2021,

Published 07-06-2021.

Copyright (c) 2021 Abhijit Patil et al. This is an open access article distributed under Creative Commons Attribution License [Attribution 4.0 International (CC BY 4.0)] 


\section{PRESENTATION OF CASE}

A 45-year-old male patient presented to the Department of Prosthodontics with a chief complaint of missing teeth, thereby having problems in mastication and aesthetics. Past medical history was insignificant and past dental history revealed that patient had undergone extraction of the grossly carious left maxillary lateral incisor, first premolar and first molar six months back. The prosthodontic diagnosis was Kennedy's class III with modification II (Pier abutment).

Intraoral examination revealed missing first premolar, left maxillary lateral incisor and maxillary first molar with left maxillary central incisor and maxillary second molar acting as terminal abutments. The canine and second premolar were the pier abutments in this scenario (Fig 1). The radiographic evaluation revealed adequate bone support on the abutment teeth.

\section{DISCUSSION OF MANAGEMENT}

Due to financial constraints, dental implants were ruled out. Hence, after discussing all the treatment options, their advantages and limitations, a seven-unit FPD using split pontic technique incorporated with non-rigid connector was planned for the patient. Exocad software was used and final prosthesis was fabricated in all ceramic FPD using computer aided milling. The risks and benefits were discussed with the patient and a written, informed consent was obtained.
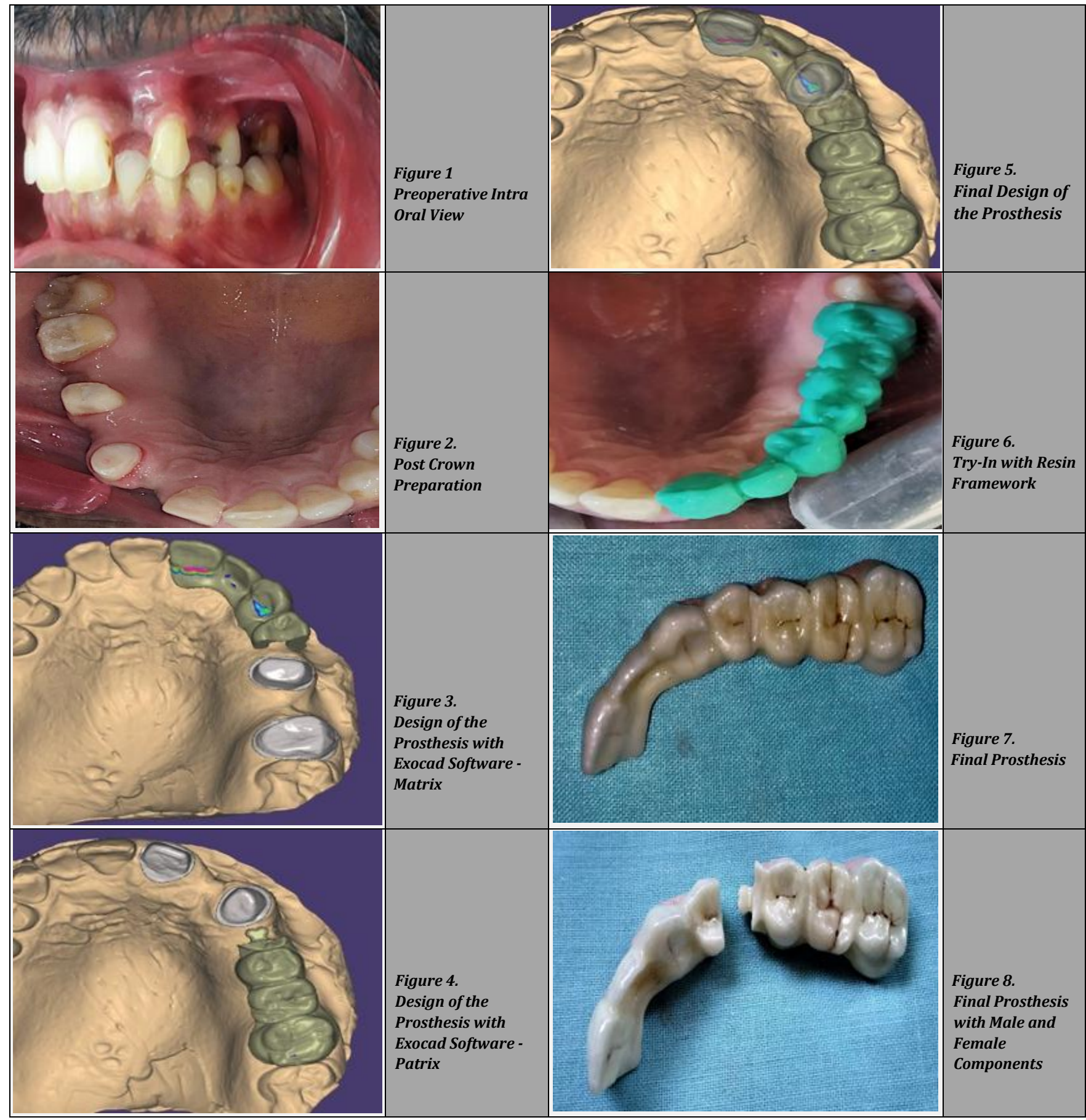


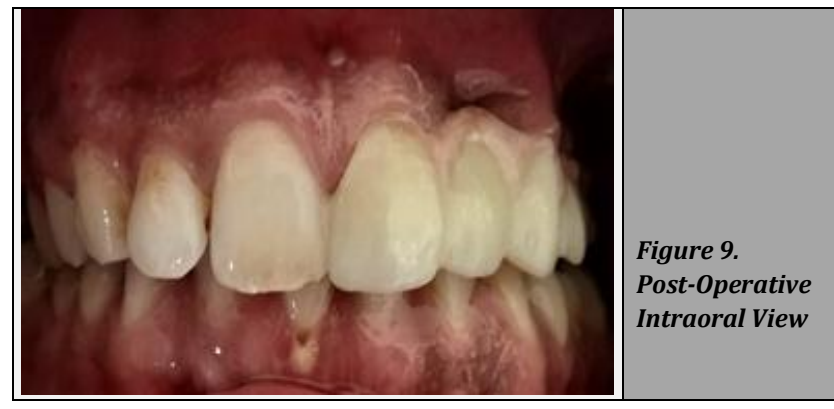

\section{Procedure}

1. Tooth preparation was carried out on the abutment teeth with equigingival margin and shoulder finish line for better aesthetics and gingival retraction was carried out with maxillary central incisor, canine, second premolar and second molar (Fig 2). Following which, impressions were made with a two-stage, double-mix, putty-light body rubber base impression material (A-Silicone, Aquasil, DENTSPLY) and were poured in a Type IV dental stone (Kalrock, Kalabhai). A face-bow transfer and interocclusal record were used to mount the master casts on a semiadjustable articulator.

2. The provisional restorations were made using a tooth coloured auto-polymerising acrylic resin and were cemented using non-eugenol temporary cement.

3. Final casts were scanned with digital scanner and images were subjected to Exocad software where final designing of the prosthesis was carried out. (Fig 3, 4)

4. Matrix and Patrix system of the connector were selected in the software and checked for parallelism.

5. Key - Keyway Connector system was incorporated in the pontic with maxillary first premolar with the split pontic technology. (Fig 5)

6. $0.25 \mathrm{~mm}$ of gap was given in the matrix and Patrix system; as under functional load, the abutments move in their respective sockets by up to $0.25 \mathrm{~mm}$.

7. After finalising the final prosthesis in the software, it was 3 - D printed.

8. Provisional framework in the resin was tried in the patient's mouth to verify proper seating. (Fig 6)

9. Final FPD was fabricated in all ceramic zirconia system using computer aided milling technology. (Fig 7,8)

10. To ensure adequate fit, anterior segment with the female component and posterior segment with the male component were assembled together.

11. Cementation was done using resin-modified cement; where anterior segment with keyway was cemented first, followed by the cementation of posterior segment with key. (Fig 9)

12. The patient was advised to maintain good oral hygiene and was recalled after a period of one week for follow-up.

\section{DISCUSSION}

Connectors are defined as "The portion of a fixed partial denture that unites the retainers and pontics." 6 They can be broadly classified as rigid connectors (solder joints or cast connector) or non-rigid connectors (precision attachment or stress breaker). Rigid connectors are most preferred between retainers and pontics while fabricating most FPDs. However, they are not indicated in all situations, like in the case of a lone standing pier abutment.

A pier abutment creates a fulcrum like situation, which can lead to failure of the weakest of the terminal abutments, and can also cause intrusion of the pier abutment. A misaligned abutment might result in devitalisation of the tooth while creating parallelism of the preparation for the prosthesis. This can be resolved with the use of intra coronal attachments as connectors.

In case of long span FPDs, the distortion and shrinkage of the porcelain on thin portions of the framework can eventually affect the fit of the prosthesis. ${ }^{7}$ Therefore, the selection of the ideal connector during treatment planning is an essential step for the success of the prosthesis. ${ }^{8}$

This case report illustrates the use of a non-rigid connector between distal portion of left maxillary first premolar pontic and mesial of second premolar retainer, where second premolar and canine act as a pier abutment and the central incisor and second molar act as terminal abutments. The selection of the appropriate shape, size, and type of the connector is crucial for the success of the FPD. ${ }^{9}$ Factors such as overload, torque, leverage, and flexing cause abnormal tension concentration, which can lead to failure of the long span FPD.

Non-rigid connectors have the advantage of transferring the shear stresses to the underlying bone rather than concentrating them in the connector. They also minimize mesiodistal torqueing of the abutment teeth and allow them to move independently. ${ }^{10}$

Different recommendations have been given by various authors for the site of placement of non-rigid connectors. Shillinburg et al. suggested the placement of a non-rigid connector on the distal aspect of the pier abutment retainer in a five-unit restoration; since positioning the non-rigid connector on either of the terminal abutments may result in the pontic acting as a lever arm. ${ }^{2}$ Whereas, Markley recommended the placement of non-rigid connector on one of the terminal retainers and not at the pier abutment, to prevent transfer of extreme loads to the relatively weak premolar abutment. $^{5}$

However, Gill advised the placement of non-rigid connector on one or both sides of the pier abutment.11 Adams proposed the use of non-rigid connector based on the clinical scenario, he recommended placement of one non-rigid connector at the distal aspect of the pier abutment, and if needed placing one more at the distal aspect of the anterior retainer. ${ }^{12}$

While Carl E Misch suggested that a non-rigid connector be placed in a conventional FPD, with the 'male' portion attached to the mesial aspect of the posterior pontic, and the 'female' portion attached to the distal surface of the pier abutment.

\section{CLINICAL SIGNIFICANCE}

When rigid connectors are used for the rehabilitation of arches with pier abutments, the occlusal load applied on the abutment teeth at one end of the fixed partial denture (FPD) will cause the pier abutment to serve as a fulcrum. This will lift the other end of a fixed partial denture like a class I lever, inducing stresses on the terminal abutments, which can lead 
to failure of the weakest of the terminal abutments, and can also cause intrusion of the pier abutment. To overcome this potential risk, an innovative, time saving and cost effective way of fabricating a non-rigid connector using Exocad software and 3-D printing of split pontic FPD is presented in this case report.

Financial or other competing interests: None.

Disclosure forms provided by the authors are available with the full text of this article at jemds.com.

\section{REFERENCES}

[1] Dange SP, Khalikar AN, Kumar S. Non-rigid connectors in fixed dental prosthesis-a case report. J India Dent Assoc 2008;2:356.

[2] Garg S, Shukla S. Restoration of arches with pier abutment using non-rigid connector. Int J Res Dent 2014;4:224-8.

[3] Banerjee S, Khongshei A, Gupta $T$, et al. Non-rigid connector: the wand to allay the stresses on abutment. Contemp Clin Dent 2011;2(4):351-4.
[4] Oruc S, Eraslan O, Tukay HA, et al. Stress analysis of effects of non-rigid connectors on fixed partial dentures with pier abutments. J Prosthet Dent 2008;99(3):185-92.

[5] Markley MR. Broken stress principle and design in fixed bridge prosthesis. J Prosthet Dent 1951;1(4):416-23.

[6] The glossary of prosthodontic terms. J Prosthet Dent 2005;94(1):10-92.

[7] Shillinburg HT, Sather DA, Wilson EL, et al. Fundamental of fixed prosthodontics. $4^{\text {th }}$ edn. Chicago: Quintessence 2012:91-2.

[8] Banerjee S, Khongshei A, Gupta T, et al. Non-rigid connector: the wand to allay the stresses on abutment. Contemp Clin Dent 2011;2(4):351-4.

[9] Malone WFP, Tylman SD, Koth DL. Tylman's theory and practice of fixed prosthodontics. $8^{\text {th }}$ edn. St Louis: Ishiyaku Euro-America 1989:74-5.

[10] Sutherland JK, Holland GA, Sluder TB, et al. A photo elastic analysis of the stress distribution in bone supporting fixed partial denture of rigid and non-rigid design. J Prosthet Dent 1980;44(6):616-23.

[11] Gill JR. Treatment planning for mouth rehabilitation. J Prosthet Dent 1952;2(2):230-45.

[12] Adams JD. Planning posterior bridges. J Am Dent Assoc 1956;53(6):647-54. 